\title{
A PARATAXE NOS ESCRITOS DO PROFETA GENTILEZA
}

\author{
PARATAXIS EN LOS ESCRITOS DEL PROFETA GENTILEZA
}

PARATAXIS IN PROPHET GENTILEZA'S WRITINGS

\author{
Ivo da Costa do Rosário* \\ Universidade Federal Fluminense \\ José Marcos Barros Devillart** \\ Universidade Salgado de Oliveira
}

\begin{abstract}
RESUMO: Neste artigo, investigamos o processo de integração de orações por meio de relações paratáticas presentes nos escritos do Profeta Gentileza. Utilizamos pressupostos teórico-metodológicos oriundos da Linguística Funcional Centrada no Uso. Propomos uma análise que compreenda a parataxe no nível discursivo, e a atuação do princípio da iconicidade na organização linguística do texto, com o aporte teórico das unidades retóricas. Objetivamos apresentar uma reflexão sobre as pressões pragmático-discursivas que atuam nas unidades constitutivas do discurso, demonstrando que o processo de parataxe é influenciado por fatores que estão além do nível estritamente linguístico. Concluímos que as orações mais curtas da parataxe facilitam a repetição e a memorização, aspecto comum dos textos religiosos e propagandísticos. Além disso, o uso da parataxe é uma estratégica compatível com o paralelismo frequentemente adotado pelo Profeta Gentileza.
\end{abstract}

PALAVRAS-CHAVE: Discurso. Parataxe. Iconicidade.

RESUMEN: En este artículo, hemos investigado el proceso de integración de las oraciones a través de las relaciones paratácticas presentes en los escritos del Profeta Gentileza. Utilizamos los supuestos teórico-metodológicos de la Lingüística Funcional Centrada en Uso. Proponemos un análisis que comprenda la parataxis en sentido discursivo, y la actividad del principio de la iconicidad en la organización lingüística del texto, con el apoyo teórico de las unidades retóricas. Queremos presentar una reflexión acerca de las presiones pragmático-discursivas que actúan en las unidades constituyentes del discurso, demostrando que el proceso de parataxis está influenciado por factores que van más allá del nivel estrictamente lingüístico. Concluimos que las oraciones más cortas de parataxis facilitan la repetición y la memorización, aspecto común de los textos religiosos y propagandísticos. Además, el uso estratégico de la parataxis es compatible con el paralelismo a menudo adoptado por el Profeta Gentileza.

PALABRAS CLAVE: Discurso. Parataxis. Iconicidad.

ABSTRACT: In this paper, we investigate the process of integration of clauses through paratactic relations found in the writings of the Prophet Gentileza. We use theoretical and methodological orientations of Usage Based Functional Linguistics. We propose an analysis including the parataxis in the discursive level, and the activity of the principle of iconicity in the linguistic organization of

\footnotetext{
* Doutor em Letras Vernáculas (UFRJ) e Estudos Linguísticos (UFF). Atualmente é docente de língua portuguesa do Departamento de Letras Clássicas e Vernáculas e docente permanente do programa de Pós-graduação em Estudos de Linguagem da Universidade FederalFluminense. E-mail: rosario.ivo3@gmail.com

** Mestre em Estudos de Linguagem (UFF) e professor assistente do Departamento de Letras da Universidade Salgado de Oliveira.E-mail:prof_jm@hotmail.com
} 
the text, with the theoretical support of rhetorical units. We aim to reflect on the pragmatic-discursive tensions acting on the constituent units of discourse, demonstrating the parataxis process is influenced by factors that are beyond the strictly linguistic level. We conclude the shorter clauses of parataxis ease repetition and memorization, a common aspect of religious and propagandistic texts. Furthermore, the strategic use of the parataxis is compatible with the parallelism frequently adopted by the Prophet Gentileza.

KEYWORDS: Discourse. Parataxis. Iconicity.

\section{INTRODUÇÃO}

Para Givón (1995, p.10), as línguas são em parte icônicas. Isso significa que, segundo o autor, os arranjos estruturais das línguas refletem, de algum modo, as suas respectivas estruturas semânticas. Esse princípio, mais modernamente, tem recebido uma atenção mais aprofundada no campo da Linguística Funcional Centrada no Uso (LFCU). Afinal, segundo Traugott e Trousdale (2013, p. 11), nas construções linguísticas, há sempre um pareamento de forma e função, que considera tanto os aspectos internos quanto os externos ao sistema linguístico.

A organização discursiva dos escritos do profeta Gentileza, fortemente pressionada pela sua visão de mundo, é um campo propício para a reflexão acerca do fenômeno da iconicidade. Como profeta, que visa a "educar" seus "filhos", o poeta popular propõe uma visão dicotômica da realidade. Nos seus textos, o uso de temas opostos, sempre ligados ao bem e ao mal, codifica uma visão binária que pode ser analisada a partir do uso das cores nas pilastras onde esse material é encontrado. Vejamos a primeira pilastra ${ }^{1}$ :

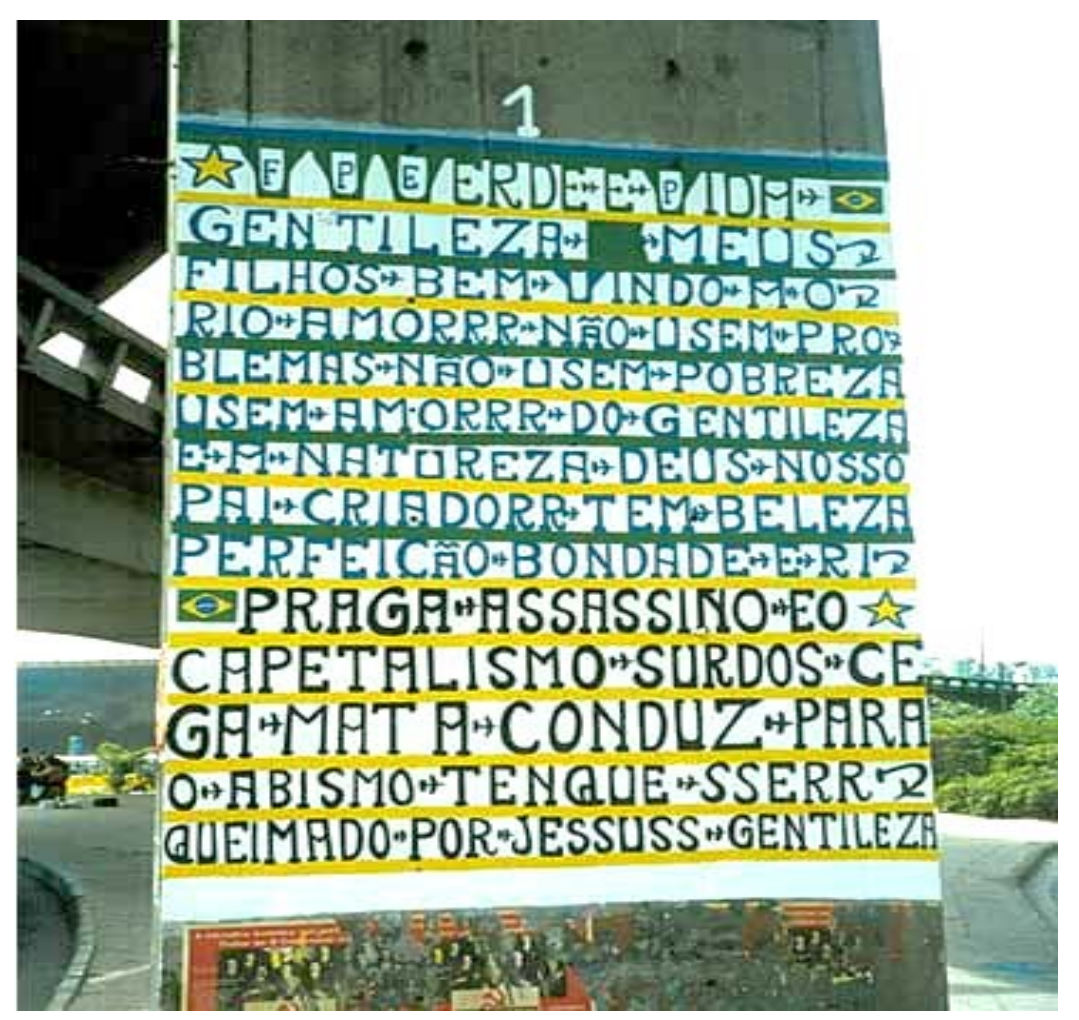

Figura 1: foto da pilastra $1^{2}$

Fonte: Rio Com Gentileza (2014)

\footnotetext{
${ }^{1}$ Na seção seguinte, faremos uma descrição mais pormenorizada do Profeta Gentileza, bem como do suporte utilizado para seus escritos.

${ }^{2}$ As fotos das pilastras que ilustram este artigo, onde estão os escritos do profeta, foram copiadas digitalmente do site Rio Com Gentileza (2014). Tanto a Figura 1 quanto a Figura 2, que antecedem a análise de dados propriamente dita, servem para ilustrar aspectos teóricos do trabalho. A partir da seção 3 (Análise de Dados), passamos a uma investigação mais pormenorizada da obra de Gentileza.
} 
Com relação ao material linguístico, na pilastra, as cores verde e azul estão ligadas ao "bem”, à vida, à natureza. Por outro lado, a cor preta está relacionada ao "mal”, à ausência de vida. A obra do autor, registrada em pilastras de viadutos, no Centro do Rio de Janeiro, desde o primeiro escrito já comprova a visão maniqueísta cultivada por Gentileza. Para Guimarães (2003, p. 109): “[...] os códigos culturais são binários, polarizados e assimétricos, ou seja, a informação de uma cor é definida mediante a oposição sintática, semântica e pragmática a outra cor, valorada em polos opostos (positivo e negativo)".

Os textos do profeta Gentileza não estão restritos ao aspecto puramente linguístico. Percebemos que os escritos são enriquecidos com outros elementos igualmente importantes. Por exemplo, as cores branca, verde e amarela, que compõem as estrelas e as linhas, são justapostas, formando uma estrutura simbólica relacionada ao patriotismo do profeta. Esse sentimento é reiterado por meio do uso da bandeira do Brasil, desenhada em quase todos os escritos. Dessa forma, há uma coerência significativa entre as escolhas do autor e seu propósito comunicativo, unindo a linguagem escrita a outras semioses.

O fluxo discursivo dos escritos de Gentileza é sancionado por essa visão de mundo e pela postura propagandística e religiosa que o escritor expõe por meio de sua persona. Ele cria uma personagem que se inscreve no discurso como porta-voz de Jesus e, por isso, pode, em nome dele, por meio de sequências injuntivas, orientar seus filhos para uma vida mais agraciada, de acordo com os padrões religiosos. Acreditamos que esse fator seja central para a escolha por construções "paralelas", dentre elas, o vínculo oracional por parataxe (DEVILLART, 2015, p. 116-117).

Nosso objetivo, neste artigo, consiste principalmente na identificação dos fatores pragmático-discursivos motivadores desses vínculos oracionais, que são mais frequentes nos textos do profeta. Também objetivamos investigar como aspectos externos ao sistema linguístico motivariam a organização do fluxo discursivo e a funcionalidade da articulação oracional por parataxe.

A título de organização, dividimos o artigo em quatro seções. Na primeira, falamos um pouco sobre o profeta Gentileza e sua obra. Na segunda, precisamos os pressupostos teóricos envolvidos na análise. Na terceira seção, partimos para a interpretação de algumas estruturas paratáticas presentes na obra do profeta. Na quarta, e última, levantamos algumas possíveis conclusões e futuros questionamentos.

\section{GENTILEZA: VIDA E OBRA}

Nesta seção, apresentamos uma pequena biografia do profeta, com especial atenção para os aspectos que possam auxiliar a interpretação linguística dos escritos. Portanto, interessa-nos saber:
a. Como Gentileza era visto pelos membros da comunidade à qual pertencia?
b. Como ele se posicionava socialmente?
c. Até que ponto os fatores acima influenciaram a construção do seu discurso?

José Datrino nasceu no dia 11 de abril de 1917, em Cafelândia, cidade do interior paulista. Dividia a vida no campo com mais dez irmãos. Teve uma infância voltada para o trabalho na e com a terra. De escolaridade primária (não sabemos ao certo até que ano escolar), começou a trabalhar muito cedo para ajudar no sustento da família.

Viveu como lavrador até os vinte anos de idade, quando decidiu mudar-se para o Rio de Janeiro. Após estabelecer-se na cidade, casou-se e teve cinco filhos. Ele obtinha seu sustento realizando fretes, principalmente nas proximidades da Rodoviária Novo Rio. Com o crescimento do negócio, abriu uma pequena transportadora no centro da cidade. Na época, possuía três caminhões, três terrenos e uma casa.

Bastante comovido com a desgraça do dia 17 de dezembro de 1961, quando o Gran Circus Norte-Americano, localizado em Niterói, pegou fogo e cerca de 400 pessoas morreram de forma desastrosa, José Datrino, segundo ele mesmo, por indicação divina, mudou seu nome para José Agradecido, o Agraciado por Deus. Segundo os relatos históricos, ele não perdeu nenhum familiar na tragédia, 
o que contradiz muitas lendas sobre esse acontecimento.

O profeta dizia ter ouvido vozes que o mandavam abandonar tudo e seguir para o local da tragédia no intuito de confortar os que sofriam. De fato, estabeleceu-se no local do incêndio com um de seus caminhões, que se tornou a sua casa. Transformou o local em um grande jardim. Segundo ele dizia, o mundo era o circo queimado, que deveria ser "reflorestado" de boas intenções, e suas flores representavam esta vida no novo mundo que nascia.

Gentileza, como ficou popularmente conhecido, pregava a abnegação dos bens "capitais dos filhos homens" para a salvação espiritual da humanidade. Vale ressaltar que, desde pequeno, acreditava que tinha uma missão muito importante no mundo. Nessa época, foi levado a "curandeiros espirituais" pelos seus pais, que perceberam que ele era "diferente" dos outros meninos. Depois de adulto, foi internado várias vezes como louco.

Ele vislumbrava uma vida terrena com mais amor, bondade e gentileza. Entre as décadas de 80 e 90, vestia-se como as figuras que conhecemos dos profetas bíblicos. O cabelo e a barba longos, a bata branca, confeccionada por ele mesmo, os estandartes nas mãos, que lembravam as tábuas dos dez mandamentos carregadas por Moisés, tudo emprestava-lhe um status quase divino.

O profeta deixou para as futuras gerações seus ensinamentos escritos nas pilastras do Viaduto do Caju, na cidade do Rio de Janeiro, fruto de seus 35 anos de pregação. Escreveu o seguinte sobre a escolha do local: "Nosso Brasil vai ser o país mais poderoso do mundo porque o Profeta Gentileza é patriota até no pé... toda bondade que vai crescer no mundo, vai ser por intermédio do Rio de Janeiro, porque o Profeta Gentileza é brasileiro." (GUELMAN, 2000, p. 57).

Para deixar seus 56 escritos, o profeta demorou dez anos (entre as décadas de 80 e 90). Em 1996, decidiu retornar a Mirandópolis (SP), próximo à sua cidade natal, onde faleceu no dia 29 de maio, aos 79 anos. Um ano depois de sua morte, seus escritos foram "pintados" de cal cinza pela COMLURB (Companhia Municipal de Limpeza Urbana do Rio de Janeiro). A intenção ela "limpar" a cidade para a visita do Papa João Paulo II. Sua produção era, até então, conhecida como pichação de um "louco religioso", sem nenhum mérito artístico, filosófico/ teológico ou linguístico.

Em janeiro de 1999, teve início o projeto RIO COM GENTILEZA, coordenado pelo Professor Leonardo Guelman (UFF), com o objetivo de restaurar os escritos que estavam praticamente destruídos. A Universidade Federal Fluminense, em conjunto com a Rodoviária Novo Rio e outras empresas, com apoio da Secretaria Municipal de Cultura do Rio de Janeiro, iniciou o programa de restauração, finalizando-o em 2000. No Decreto n 19.188, de 27 de novembro de 2000, foi determinado, pelo prefeito Luiz Conde, o tombamento das “[...] 55 (cinquenta e cinco) pinturas/escritos de autoria de José Datrino, conhecido popularmente como Profeta Gentileza localizadas na estrutura do viaduto do Caju”(RIO DE JANEIRO, 2000).

Muitas pesquisas sobre o "universo" de Gentileza já foram realizadas, e sua obra hoje é reconhecida pelo valor cultural e artístico que empresta à cidade do Rio de Janeiro. Entre essas, temos a dissertação de mestrado de Guelman (1997) e a obra Brasil: tempo de Gentileza (2000), do mesmo autor. Ambos descrevem Gentileza como um artista que se formou a partir de um mito.

Gentileza foi uma personagem do fim do século, quando toda a mística com relação a esse evento pairava sobre a sociedade. O suposto final do mundo no ano 2000 instigava os noticiários e os comentários pelas ruas. Parece que Gentileza personificou a acusação desse mundo em chamas, que seria destruído como o circo. Disse ele: "A derrota de um circo queimado é um mundo representado, porque o mundo é redondo e o circo arredondado” (GUELMAN, 2000, p. 45).

Uma dicotomia pairava sobre a figura dele, como nos diz Carvalho (2004, p. 12, grifos nossos):

Por um lado, poderia parecer que as condições de produção no discurso de Gentileza asseguravam-lhe o "título" de profeta; por sua aparência e lugar bastante visível e de grande circulação de veículos e pessoas onde pintava suas pregações: viadutos, muros e pilastras. Por outro lado, essas mesmas condições de produção o colocariam em uma posição de louco, já que essas palavras não eram proferidas e sim pintadas, como matérias plásticas, 
justapostas, sem conexão sintática entre si, não formando efetivamente enunciados que poderiam configurar uma profecia.

Em nossas pesquisas, confirmamos que as representações sociais de Gentileza giravam em torno de um mito. Lemos algumas declarações sobre ser ele um homem que atacava verbalmente, e até fisicamente, as pessoas na rua. Em outras, encontramos a figura de um homem terno que só queria divulgar o amor. Há, sem dúvida, contradições ou diferentes perspectivas sobre esses pontos de sua biografia.

Leonardo Boff via em Gentileza características típicas de profetas bíblicos. Dado Amaral, cineasta, dizia que ele era um louco com uma articulação, coerência, mensagem, com um discurso elaborado. Para Arthur Bispo do Rosário, Gentileza era um artista. (PEREIRA, 2008). Já para outros, principalmente para as pessoas que presenciaram suas pregações, o profeta delirava como fruto de uma crença religiosa intensa.

Não chegamos a uma conclusão sobre a saúde mental de Gentileza, nem esse é nosso objetivo. Para os que o chamavam de louco, ele respondia: "Sou maluco para te amar e louco para te salvar". Louco ou profeta, Gentileza construiu um legado cultural representado pela língua, que agora nos propomos a investigar em alguns de seus aspectos. Sendo assim, identificamos alguns pontos que merecem destaque na representação social do profeta.

Com relação à obra de Gentileza, devemos destacar que se trata de uma verdadeira intervenção artística numa zona coberta de sujeira e poluição (visual, atmosférica e sonora): as imediações da rodoviária Novo Rio. Essa área degradada da capital fluminense contrasta com a predominância de cores alegres e fortes que procuram motivar, por si sós, uma relação mais agradável com a vida, já tão rotinizada e penosa.

Embora o profeta tenha escrito outros textos, principalmente poesias e relatos pessoais, os dados coletados para esta pesquisa são constituídos por 56 textos-murais pintados nas pilastras do Viaduto do Caju entre as décadas de 80 e 90 . Os dados são públicos e não manipulados. Segundo Guelman (2000, p. 38), eles foram escritos numa sequência lógica aparente, por isso o conjunto pode ser chamado de "livro urbano".

Os escritos recuperam estruturas dos textos doutrinários e religiosos, em que é comum o uso da persuasão e da ilustração (por meio de metáforas, analogias e parábolas) para transmitir ensinamentos. Tendo essas características como parâmetros, para fins deste estudo, classificamos a obra do profeta como religioso-doutrinária, em que os vocativos e as sequências injuntivas predominam. Assumimos que os escritos de Gentileza são uma espécie de hieróglifos modernos, com função religiosa e didática.

Antes de encerrarmos esta seção, vale recuperarmos um importante ponto sobre a produção linguística de Gentileza. Para Carvalho (2004, p. 12, grifos nossos), citado anteriormente, as “[...] condições de produção o colocariam em uma posição de louco, já que essas palavras não eram proferidas e sim pintadas, como matérias plásticas, justapostas, sem conexão sintática entre si”. É verdade que Gentileza frequentemente utilizava formas paratáticas e justapostas em seu modo de escrever, entretanto, essas formas não podem ser consideradas como "sem conexão sintática", visto que a parataxe congrega uma considerável complexidade de relações semânticas (LONGHIN-THOMAZI, 2011, p. 234) em um arranjo sintático com características próprias, como ficará mais claro ao longo do artigo.

Nesta seção, procuramos traçar um quadro que situasse o autor, a obra e seus propósitos pragmático-discursivos no contexto de produção. Tendo esse quadro em tela, na próxima seção, partimos para a base teórica que orienta a pesquisa. 


\section{PRESSUPOSTOS TEÓRICO-METODOLÓGICOS}

\subsection{A LINGUÍSTICA FUNCIONAL CENTRADA NO USO (LFCU)}

Para a LFCU, o estudo da língua, em nenhum momento, pode ser desvinculado do uso e de seus fatores externos. A língua é vista como um instrumento de comunicação maleável por conta das situações comunicativas que a pressionam. Essas pressões acabam por motivar a estrutura gramatical. Assim, a explicação para as estruturas gramaticais e discursivas deve ser procurada nas situações comunicativas, ou seja, nas condições pragmático-discursivas às quais os falantes estão submetidos (CUNHA; BISPO; SILVA, 2013)

A LFCU parte do pressuposto de que as línguas devem ser observadas levando em consideração tanto o contexto linguístico quanto a situação extralinguística. Considerando que a linguagem é uma atividade sociocultural, entendemos que a estrutura está a serviço de funções cognitivas e comunicativas (ROSÁRIO; OLIVEIRA, 2016). Essa estrutura é parcialmente motivada e icônica, ou seja, a estrutura é relacionada ao sentido, e o sentido é contextualmente presente.

A língua é baseada nas experiências do indivíduo com o mundo. A habilidade desse indivíduo em construir estruturas linguísticas seria a mesma encontrada em outras habilidades, como a de pintar um quadro ou trocar um pneu. Esses procedimentos seguem uma ordenação, uma sequência analógica que é apreendida à medida que se tem contato com o mundo (BYBEE, 2010, p. 49 - 51).

Assim, a língua é uma espécie de rede, balizada por princípios interacionais, em que esquemas mentais se conectam e formam estruturas que refletem essa conexão. Os pesquisadores, então, devem se preocupar não só em entender a estrutura da linguagem, como também a relação dessa estrutura com o mundo que simboliza e o seu processamento (ROSÁRIO; WIEDEMER, 2014).

Nossa pesquisa insere-se em um modelo descritivo-analítico, e a metodologia leva em conta a interdependência de fatores comunicativos, cognitivos e sociais. Com base em nosso objeto de investigação, procuramos identificar e avaliar como esses fatores regulam a organização discursiva dos textos de Gentileza.

Apesar de a escrita de Gentileza não se filiar ao que preconiza a língua padrão, há uma organização que pode ser interpretada por meio da relação forma-função. Assim, propomos investigar essa relação a fim de demonstrar a coerência dos textos do profeta. Segundo Martellotta (2009), a análise feita pelas linhas funcionalistas (na qual esse trabalho se insere) é essencialmente qualitativa com suporte quantitativo, o que é evidenciado pelo perfil do corpus desta pesquisa, visto que nossa análise quantitativa fica restrita ao número de pilastras pintadas pelo profeta, ou seja, 56 ao todo.

Devemos destacar que, em uma perspectiva funcionalista, em que casos híbridos e fronteiriços são caros e bastante relevantes, nem sempre é possível precisar com exatidão a que categoria determinados dados se inserem. Logo, a presente análise pauta-se em uma perspectiva que considera as categorias como tendo limites difusos e sem contornos muito bem definidos. Essa perspectiva está na base da categorização linguística de base funcional (TAYLOR, 1992).

Para Martelotta (2009), não apenas a interdependência de fatores de natureza comunicativa, cognitiva, histórica, social e estrutural deve ser levada em conta na abordagem funcionalista. Devemos também analisar esses fatores na atuação contextual, em que entram os aspectos semânticos e pragmático-discursivos. Isso naturalmente carreia uma maior complexidade para a análise, com impasses e algumas dificuldades. Por outro lado, torna-a mais abrangente e completa.

Interessa-nos saber como o profeta constrói o seu discurso e como as regularidades são apresentadas em sua obra. Consideramos que Gentileza usa estratégias comunicativas em seu texto para atingir fins comunicativos específicos. As estratégias passam pela relação entre homem e mundo natural para determinar o mundo linguístico (GIVÓN, 1995). Essa perspectiva está em consonância com uma visão teórica mais moderna, como a de Traugott e Trousdale (2013), quando afirmam que a língua é uma rede conceitual, uma espécie de quadro em que se intercambiam aspectos internos ao sistema linguístico e fatores externos à língua. 


\subsection{A ICONICIDADE}

Gentileza direciona seu discurso a quem ele chama de filhos, o que colabora para marcar semântica e pragmaticamente a característica religiosa de sua obra. O seu texto serve ao propósito de aconselhar as pessoas, para que abandonem determinadas posturas ("NÃO USEM PROBLEMAS") e adotem outras (“USEM AMOR"). As pressões pragmático-discursivas começam quando o profeta constrói uma persona que incorpora um discurso com propósito didático-religioso, por isso o uso da língua vem acompanhado de função pragmática específica. O discurso seria, então, a forma de Gentileza se mostrar como profeta e, assim, poder agir sobre os leitores, seus filhos.

Nesse ponto, assumimos o pressuposto teórico da iconicidade como meio capaz de nos conduzir à investigação de como as formas linguísticas estão relacionadas às funções que exercem. Para nós, as propriedades de semelhança e analogia entre signo e referente, características do ícone, estariam na natureza da linguagem e agiriam basicamente no momento da interação. Para a LFCU, a iconicidade é definida:

[...] como a correlação natural entre forma e função, entre código linguístico (expressão) e seu designatum (conteúdo). Os linguistas funcionais defendem a ideia de que a estrutura da língua reflete, de algum modo, a experiência. Como a linguagem é uma faculdade humana, a suposição geral é que a estrutura linguística revela as propriedades da conceitualização humana do mundo ou as propriedades da mente humana. (FURTADO DA CUNHA; RIOS DE OLIVEIRA; MARTELOTTA, 2003, p. 29)

Peirce (apud WILSON; MARTELOTTA, 2011) propõe que a sintaxe das línguas naturais não é totalmente arbitrária, e sim isomórfica. Sendo assim, a relação entre forma e função seria transparente. Na LFCU, entendemos esse isomorfismo de forma moderada, pois, muitas vezes, fica difícil identificar o designatum na estrutura. Consideramos que nas línguas humanas os princípios mais icônicos (cognitivamente motivados) interagem com princípios mais simbólicos (cognitivamente arbitrários).

Defendemos que a iconicidade é um processo mais primitivo de representação da realidade, por ser o ícone o produto de um processamento cognitivo mais simples do que o símbolo (seguindo a tipologia de Peirce). O ícone, assim como o índice, é menos arbitrário do que o símbolo. Assim, a iconicidade teria motivado o início das construções linguísticas, que rumariam em direção à arbitrariedade e à abstração simbólica do alfabeto.

A primeira língua deve ter sido de motivação icônica, muito antes do alfabeto fonético. Por exemplo: os hieróglifos são mais icônicos do que a escrita alfabética, pois a semelhança entre o pictórico e o conceito é muito mais transparente. Por conta dessa motivação, os princípios icônicos seriam mais individuais e criativos, por isso mais salientes no discurso. Já os princípios simbólicos, por serem mais coletivos e automatizados, seriam mais salientes na gramática.

Inicialmente, acreditava-se que a iconicidade estaria baseada na relação "um para um", apenas uma forma para um sentido e viceversa. Essa versão inicial e mais radical, entretanto, foi reformulada pela constatação de que podem existir duas ou mais formas de articular sentidos correspondentes. Essa nova versão pressupõe uma maior liberdade de escolha do usuário no momento da interação, bem como uma maior adequação às necessidades expressivas.

As formas linguísticas não só refletem as funções, como também são pressionadas por essas funções. Se algo é posto em uso, é consequência de alguma função. As formas desempenham, assim, papéis no discurso, que tentam ser explicados a partir do princípio da iconicidade. Na versão mais branda (GIVÓN, 1984), esse princípio é subdividido em:

I. Subprincípio da quantidade: quanto maior a quantidade de informação, maior será a quantidade de forma. Já que a estrutura exprime o conceito que expressa, o que é mais complexo e não esperado na interação é expresso por mecanismos linguísticos mais complexos. 
II. Subprincípio da ordenação linear: a informação mais importante tende a ocupar o primeiro lugar na construção do discurso. A ordem dos elementos revela a ordem de importância para o usuário. Esse subprincípio não só está vinculado às necessidades expressivas e aos propósitos discursivos dos usuários, como também ao tipo de texto produzido. Por exemplo, em narrativas, a sucessão dos acontecimentos é responsável pela ordem do texto.

III. Subprincípio da integração: conteúdos mais próximos cognitivamente também serão mais integrados no nível da codificação. O que está mentalmente junto se apresenta sintaticamente junto.

A iconicidade fornece-nos suporte teórico para a compreensão de como os escritos analisados possuem marcas discursivas motivadas por fatores comunicativos e cognitivos. As estruturas linguísticas codificam os propósitos pragmático-discursivos do profeta Gentileza. Deve-se destacar que Gentileza não usa pontuação segundo a norma padrão. Isso interfere na descrição linguística, ainda mais quando se trata de integração de orações, mas ao mesmo tempo, consideramos que essa estrutura, mais ambígua, torna o texto um objeto lúdico e criativo, capaz de atender a necessidades comunicativas específicas.

Como a falta de pontuação formal atrelada ao sentido pragmático e criativo dos textos traduz-se em uma dificuldade para análise, tomamos como base o conceito de unidade retórica, de Matthiessen e Thompson (1988), desenvolvido pela Teoria da Estrutura Retórica (RST), tema da próxima subseção.

\subsection{UNIDADES RETÓRICAS}

Matthiessen e Thompson (1988) propõem uma perspectiva de análise das orações não-encaixadas segundo um conjunto de relações textuais. Para eles, a organização retórica do discurso reflete-se na combinação de orações. A relação retórica entre partes do texto está ligada ao funcionamento deste como meio de atingir objetivos comunicativos. Para identificar essa relação, o texto é dividido em unidades retóricas, que podem ser ordenadas por uma relação núcleo-satélite ou por uma relação de listagem.

Os autores (cf. HALLIDAY, 1985) postulam que há dois tipos de interdependência oracional: a projeção e a expansão. A segunda pode ser representada por meio de três diferentes mecanismos: elaboração, extensão e realce. Na elaboração, uma oração elabora o significado de outra oração, reformulando-a, comentando-a ou especificando-a. Na extensão, uma oração estende o significado de outra ao acrescentar algo novo, que pode representar uma exceção ou oferecer uma alternativa. Na expansão por realce, uma oração realça o significado de outra ao fornecer traços circunstanciais.

Vejamos o escrito abaixo: 


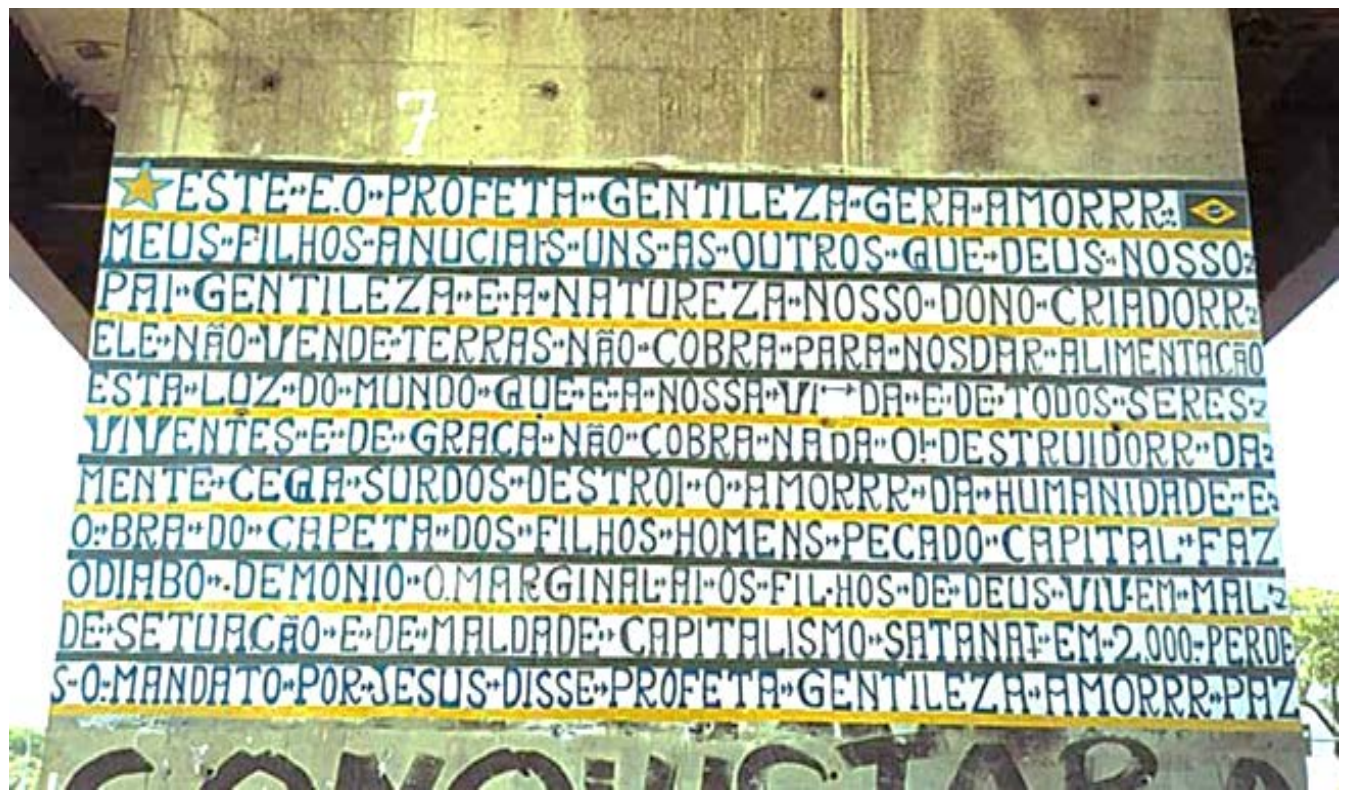

Figura 2: foto da pilastra 7

Fonte: Rio Com Gentileza (2014)

Dividimos o mural em três setores:

Setor 1: apresentação / saudação - 1 linha;

Setor 2: mensagem;

Setor 3: assinatura - última linha.

O setor 1 funciona como uma espécie de apresentação, de preparação, um título ou saudação para o que vem em seguida. O setor 3 aparece como uma espécie de assinatura, que reforça a posição de Gentileza como enviado de Deus. No setor 2, que ocupa a posição central do mural, há o que chamamos de mensagem, na qual nossa análise se concentrará.

Em parte da mensagem temos:

1. MEUS FILHOS ANUNCIAIS UNS AOS OUTROS QUE DEUS NOSSO PAI GENTILEZA É A NATUREZA NOSSO DONO CRIADOR (linhas 2 e 3 )

2. ELE NÃO VENDE TERRAS (linha 4)

3. NÃO COBRA PARA NOSDAR ALIMENTAÇÃO (linha 4)

4. ESTA LUZ DO MUNDO (QUE E A NOSSA VIDA E DE TODOS OS SERES VIVENTES) E DE GRAÇA NÃO COBRA NADA (linhas 5 e 6 )

Esquematizando esse trecho em unidades retóricas ou informacionais teríamos:

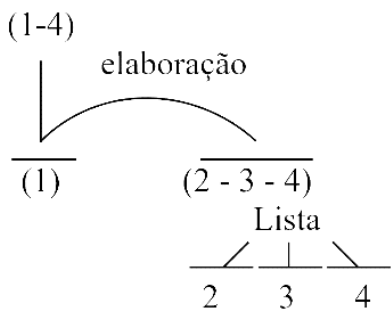


As unidades 2, 3 e 4, em conjunto, funcionam como elaboração da unidade 1, exemplificando-a, e são postas em lista, numa organização por parataxe. Na parataxe, teríamos a unidade 1 como a ideia primária, e as unidades 2, 3 e 4 como os segmentos que ampliam o sentido do segmento anterior.

Retornando ao texto, vejamos o conteúdo da unidade 5:

\section{O DESTRUIDOR DA MENTE CEGA SURDOS DESTRÓI O AMOR DA HUMANIDADE (linhas 6 e 7)}

Essa é uma unidade que está em contraste com o conjunto anterior, pois estabelece uma oposição semântica entre o bem (Deus), exposto pelo conjunto (1-4), e o mal (diabo). Dentro dessa unidade, vemos que também há uma relação de lista (semanticamente crescente): cega surdos (ensurdece) e destrói o amor da humanidade.

Os textos de Gentileza, segundo a análise por unidades retóricas, são basicamente formados por estruturas paralelas, que, como já havíamos dito anteriormente, aparecem na organização dos murais, tanto na plástica quanto no paralelismo linguístico, de cunho sintático-semântico. Essa análise das unidades retóricas auxilia na interpretação dos textos do profeta no sentido de que, na falta de pontuação formal, tenta estipular vínculos oracionais a partir não só de traços sintáticos, mas considerando, também, traços semânticos, discursivos e pragmáticos (DEVILLART, 2015).

\subsection{PARATAXE}

De acordo com Halliday (1985), há dois tipos de combinação entre orações: a parataxe e a hipotaxe. No primeiro caso, a relação é estabelecida por elementos de igual estatuto, sem que um dependa do outro. No segundo, os elementos não têm o mesmo estatuto, já que um modifica o outro, ou seja, o modificador depende do modificado. Halliday também fala em encaixamento, ou seja, quando uma oração funciona como elemento constituinte de outra.

Lehmann (1988) e Hopper e Traugott (2003) igualmente adotam uma distinção entre parataxe e hipotaxe. Ao primeiro termo, associam as noções de autonomia, ausência de relação hierárquica, menor dependência e integração. Com relação à hipotaxe, o fenômeno seria definido como um caso de dependência relativa, maior integração, maior dependência.

Ao contrário do que alguns gramáticos afirmam, os segmentos paratáticos, em geral, não permitem inversão de ordem, pois isso acarreta prejuízo de natureza semântica ou pragmática. Atento a esse importante aspecto, Halliday (1985) afirma que o segmento que aparece primeiramente na sequência paratática é chamado de primário ou inicial. O segmento seguinte é denominado secundário ou de continuação. Vale destacar que os termos apresentados não fazem referência a juízo de valor ou grau de importância.

Recuperando o exemplo anterior, temos:

\section{MEUS FILHOS ANUNCIAIS UNS AOS OUTROS QUE DEUS NOSSO PAI GENTILEZA É A NATUREZA NOSSO DONO CRIADOR}

2. ELE NÃO VENDE TERRAS

3. NÃO COBRA PARA NOSDAR ALIMENTAÇÃO

A unidade 1 seria a primária ou inicial, pois ela veicula informação importante para a decodificação das unidades 2 e 3, que seriam as secundárias ou de continuação. O pronome na unidade 2 é anafórico e está relacionado a DEUS, presente na unidade 1. Já na unidade 3, o pronome é suprimido (por questão de economia linguística e coesão textual). Comprovamos que existe, de fato, um vínculo semântico entre as orações, e a inversão das unidades prejudicaria o fluxo discursivo, logo há uma ordenação linear, como pressupõe o subprincípio da iconicidade. 
Uma questão que ainda precisa ser discutida, nesse âmbito, é a tese da suposta maior "simplicidade" da parataxe em relação à hipotaxe e ao encaixamento. Quanto a essa questão, Longhin-Thomazi (2011, p. 235) afirma:

[...] recupero uma discussão antiga, um tanto cercada de estereótipos, que consiste em atribuir simplicidade à parataxe e complexidade à hipotaxe e em sustentar que entre elas haveria uma passagem progressiva - da composição menos para a mais complexa - observável na filogênese e na ontogênese (LA FAUCI, 2007). Desses pressupostos derivam as afirmações de que a parataxe é um traço da sintaxe da língua falada, da língua das crianças e dos aprendizes, e também das línguas históricas em suas fases pretéritas. Juntamente com La Fauci (2007), entendo que a fragilidade dessas afirmações e que o tipo de contraste que elas alimentam entre parataxe (sintaxe menos rica) e hipotaxe (sintaxe mais rica) se devem, em grande parte, à desconsideração das tradições textuais e à correlação equivocada que se estabelece entre simplicidade e oralidade.

Comungamos com a posição de Longhin-Thomazi (2011), ao afirmar que a parataxe não é uma estratégia dotada de menor complexidade em relação à hipotaxe e à subordinação. Em outras palavras, as construções paratáticas não são "pobres" no que concerne à veiculação das informações. Ao contrário, a parataxe é uma estratégia acertada para a codificação de todo binarismo do texto de Gentileza, em suas posições marcadamente maniqueístas.

\section{ANÁLISE DE DADOS}

Ao analisarmos o corpus sob a perspectiva das unidades retóricas, constatamos que há forte predominância de estruturas paratáticas. No total de 56 escritos, foram identificados 51 vínculos por parataxe, 15 por encaixamento ou subordinação e apenas 1 caso por hipotaxe.

Distribuição de frequência de acordo com o tipo de relação entre orações

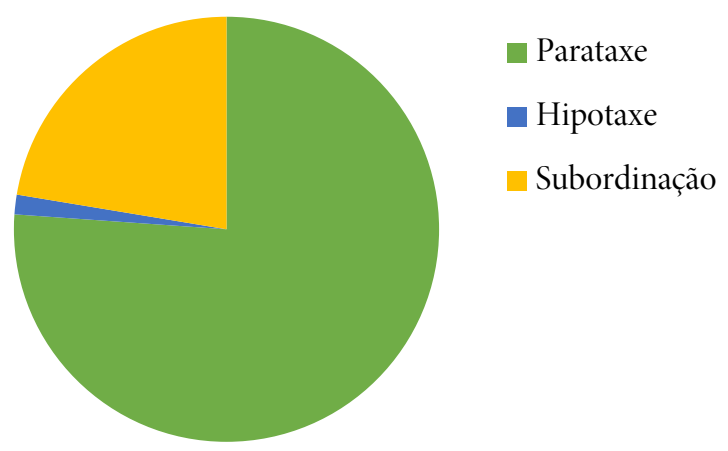

Gráfico 1: Relações entre orações

Fonte: produzido pelos autores.

Esses dados, de base quantitativa, corroboram uma de nossas principais hipóteses: a de que os escritos do Profeta Gentileza seriam de caráter fortemente paratático. Essa constatação atrela-se à ideia de que a organização informacional está bastante vinculada a aspectos pragmático-discursivos e cognitivos próprios do discurso menos integrado, menos hierárquico e menos dependente do ponto de vista sintático.

Uma das razões para o uso maciço desse modo de organização discursiva seria o didatismo, frequente em textos religiosos, e mais bem desenvolvido, para fins pragmáticos, por meio de construções paratáticas. Assim, há, de fato, motivações externas ao sistema linguístico que sancionam, no caso dos escritos do Profeta Gentileza, o uso preferencial de construções paratáticas, e não hipotáticas 
ou subordinadas. Dentre essas motivações, estaria a oposição entre o "bem" o o "mal", entre a "boa" e a "má conduta", que conduzem o texto ao efeito de permanente paralelismo, que está no cerne do processo de coordenação.

Isso também nos leva a refletir sobre a correspondência forma-função na observação do princípio da iconicidade. Fatores de ordem cognitiva são levados em conta quando pressupomos que a estrutura da língua é determinada pelas experiências adquiridas no contato com o mundo e arquivadas na memória. As construções usadas pelo profeta são reflexos de estruturas cognitivas apreendidas nas relações sociointerativas e adaptadas a propósitos pragmático-discursivos próprios.

Voltando à nossa reflexão sobre a plástica dos escritos do profeta, identificamos que existe uma dicotomia entre o concreto das pilastras e o ambiente urbano, que simbolizariam o cotidiano (o material e o ritualizado), e o colorido dos painéis, com uma significação ligada à transgressão, ao diferente, ao novo. Essa dicotomia pode estar relacionada ao questionamento da rotina diária, apreendida no local escolhido por Gentileza: a rodoviária e o trânsito caótico do centro da cidade do Rio de Janeiro. Trata-se de um local onde impera o discurso automatizado nas relações humanas. As pessoas pouco se cumprimentam, pois o corre-corre do cotidiano as afasta da gentileza com o outro. Talvez seja propósito do profeta a subversão dessa "ordem" e a reestruturação dessas relações. Para tanto, usaria a oposição como estratégia discursiva para fins didáticos (DEVILLART, 2015, p. 103).

No discurso, as ideias de Gentileza são basicamente codificadas por sequências declarativas e por sequências injuntivas. As sequências declarativas servem como uma espécie de esclarecimento sobre o mundo material e espiritual, já as injuntivas funcionam como conselhos dirigidos aos leitores. $O$ aspecto comum é que ambas as sequências são usadas para codificar sentidos opostos.

Vejamos abaixo:

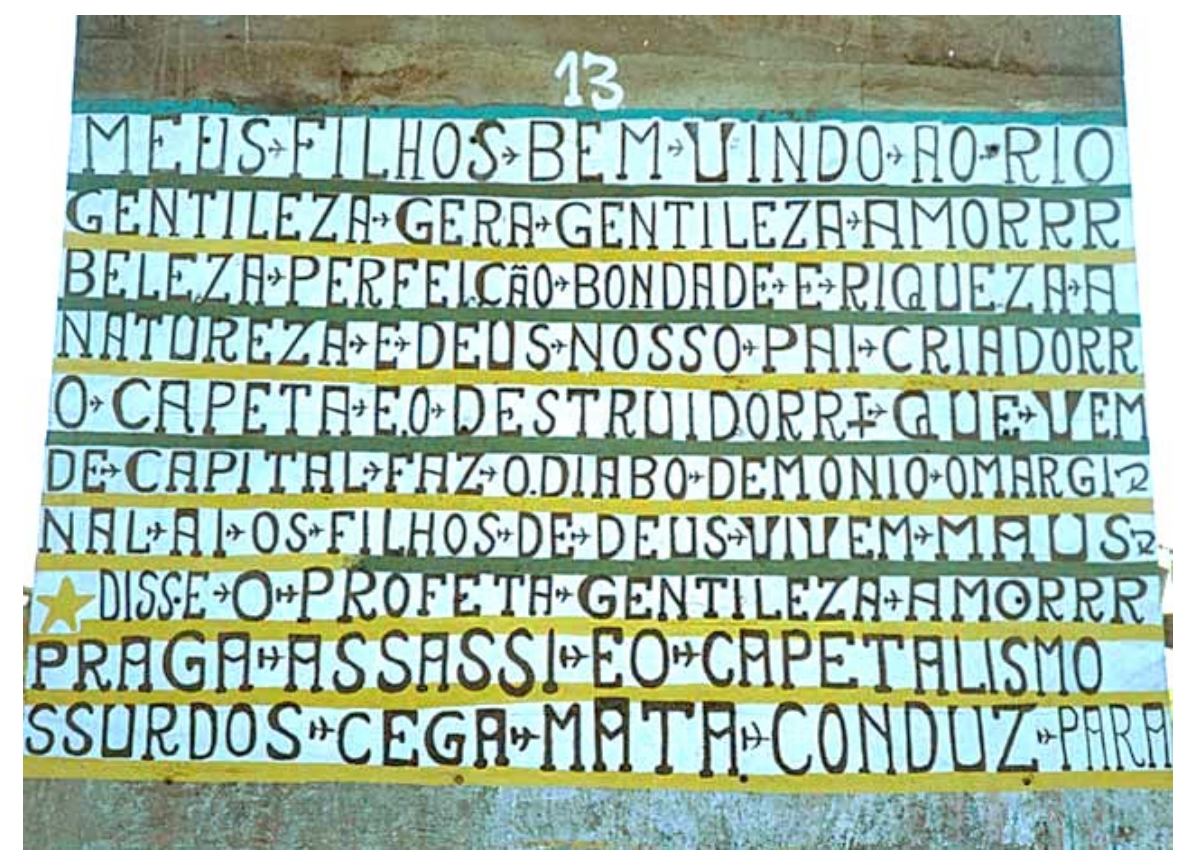

Figura 3: foto da pilastra 13

Fonte: Rio Com Gentileza (2014)

Em primeiro lugar, na cadeia sintagmática, o profeta expõe ideias relacionadas a gentileza, amor, Deus e Natureza. Logo em seguida, aparecem conceitos ligados ao mal, como capeta, diabo, destruidor. Selecionando as unidades que compõem essa oposição central, temos: 
Pelo subprincípio da integração, o que é processado cognitivamente junto é posto sintaticamente junto. Gentileza descreve o bem para depois falar sobre o mal. Isso se daria por conta da intenção comunicativa de demonstrar o mundo, que, segundo ele, não era percebido pelos seus filhos.

Esse exemplo serve para que possamos diferenciar o tratamento organizacional que Gentileza dá ao seu discurso. Nas sequências declarativas, as orações com carga semântica positiva aparecem em primeiro lugar na cadeia sintagmática; já nas injuntivas, a ordem se inverte. Isso ocorre na pilastra abaixo:

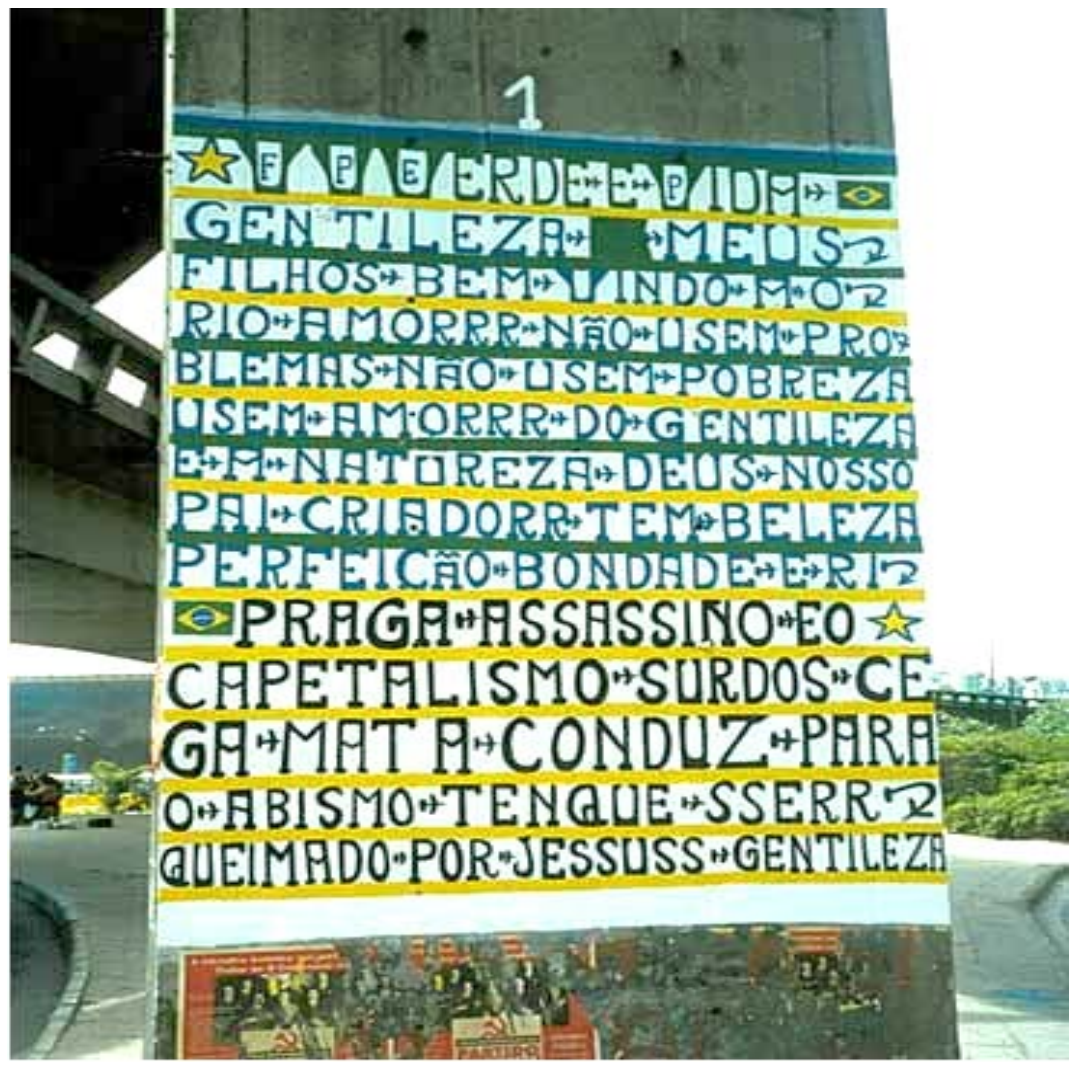

Figura 4: foto da pilastra 1

Fonte: Rio Com Gentileza (2014)

Na figura 4, fica clara a oposição entre as cores das letras (verde e preta). O verde é vida, como está na primeira linha, e o preto está relacionado ao conteúdo semântico ligado ao mal, representado por palavras como praga, assassino, mata e abismo (linhas 10, 11, 12 e 13). Para nós, essa simbologia seria transferida para o nível discursivo. Observemos:

1- NÃO USEM PROBLEMAS (linha 4)

2- NÃO USEM POBREZA (linha 5)

3- USEM AMOR DO GENTILEZA (linha 6)

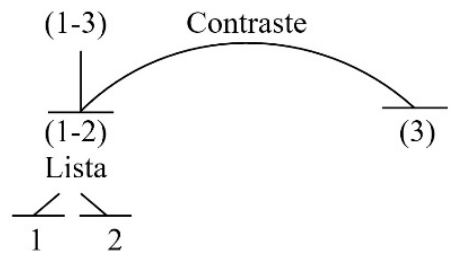

De modo geral, todas as três unidades estão vinculadas por parataxe, mas sob a perspectiva das unidades retóricas, podemos dizer que, nas unidades 1 e 2, há uma representação em lista, e a unidade 3 funciona como oposição (ou contraste) em relação a elas. Um caso similar é apresentado no escrito 3 (figura 5): 


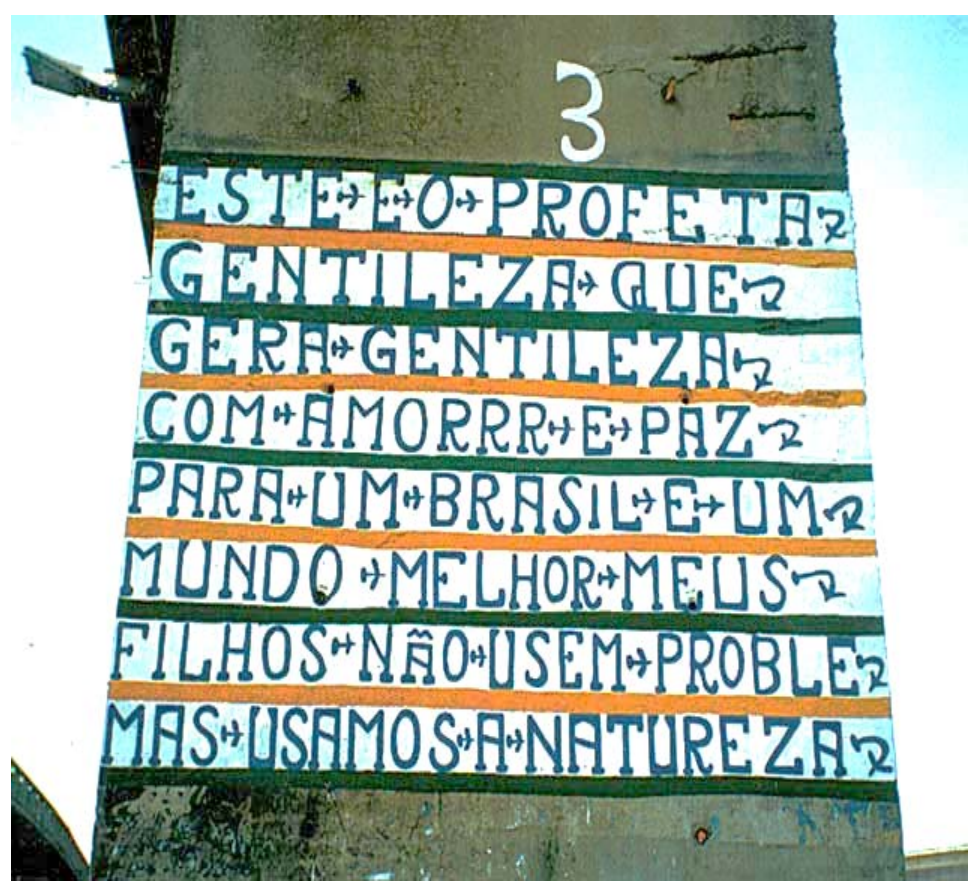

Figura 5: foto da pilastra 3

Fonte: Rio Com Gentileza (2014)

Tanto o exemplo da figura 4 quanto o da figura 5 apresentam parataxe, que parece ser mais funcional ao propósito do escritor. Quando pensamos que Gentileza explorava em seus textos o contraste entre o bem e o mal, o certo e o errado, Deus e o diabo, podemos supor que essa oposição, advinda dos dogmas religiosos, é muito mais bem exposta por meio da estrutura da língua por vínculos sintáticos menos integrados, ou seja, pela parataxe, codificada nos escritos de forma bastante paralelística.

As adversativas constituem a forma canônica ou mais prototípica, no discurso formal, para a exposição da ideia de contraste semântico. Por outro lado, como vimos na figura 5 , a falta de conectores adversativos típicos não compromete a interpretação do texto, pois o contexto ${ }^{3}$ se encarrega de veicular o valor contrastivo, tanto no nível semântico quanto pragmático.

Os ensinamentos do profeta, no que diz respeito à ideia de adversatividade, opõem sentidos no fluxo discursivo, e esses sentidos estão sujeitos a uma ordem preferencial. Assim, nas sequências injuntivas, como nas figuras 4 e 5 , as unidades informacionais que codificam a ideia do errado (mal) aparecem primeiramente, e as que codificam o certo (bem) vêm em posição posterior.

Para Oliveira (2009, p.90), desde os antigos gregos, a ordem afirmação-negação “[...] já era preservada como um apelo cognitivo de processamento de informações de contraexpectativa, comprovando-se pelas palavras de Aristóteles (OLIVEIRA, 2009, p.90): “" [...] a primeira é a afirmação, a negação é a seguinte’ ”. Essas construções se emparelham de uma forma já institucionalizada e o subprincípio da ordenação linear parece ditar essa sequência preferencial (afirmativa-negativa), com base em conceptualizações humanas do mundo.

Entretanto, o que acontece é o contrário na organização das sequências injuntivas nos textos analisados. Um pressuposto givóniano (GÍVON, 1995, p. 369) postula que a ordem temporal em que os eventos ocorrem será refletida na ordem da codificação linguística. Logo, os "filhos" erram antes de serem repreendidos e de terem a possibilidade de alcançarem o certo. A ordenação icônica vai do que é errado para o que é certo. É como se a segunda oração (oração secundária ou de continuidade) retomasse a informação da primeira, apagando-a e retificando-a por meio de contraste.

\footnotetext{
${ }^{3}$ Entendemos por contexto o conceito referido por Traugott e Trousdale (2013, p. 196) e definido por eles como "entorno linguístico", em que se inclui sintaxe, morfologia, fonologia, semântica, inferência pragmática, modalidade e contextos sociolinguísticos e discursivos.
} 
Considerando fatores internos ao sistema, poderíamos dizer que as orações paratáticas podem ser comutadas e podem sofrer alteração na sua ordem de colocação, mas se levarmos em conta os fatores pragmáticos, veremos que a comutação quebraria a coerência e a organização discursiva. A escolha da ordem no fluxo discursivo está em consonância com as representações de Gentileza como enviado de Jesus. Ele é aquele que pode apontar o que acontece de mal e tem o poder de direcionar os homens e as mulheres, por meio da injunção, ao caminho do bem.

Gentileza, seguindo os seus valores, percebe o que está errado e depois ensina o correto. Isso mostra que, nos vínculos por parataxe, a ordem das unidades informacionais pode ser iconicamente motivada, porque os segmentos são organizados segundo uma ordem temporal e cognitiva. Nesse sentido, a comutação da ordem das orações causaria prejuízos pragmáticos e uma possível anarquia na cadeia sintagmática.

Levamos também em conta que as construções paratáticas são sequências relativamente curtas, de estrutura semelhante, que servem, geralmente, para expor ideias que vão se acumulando no fluxo discursivo. Assim, o subprincípio da quantidade atuaria na enumeração de construções de igual estatuto no eixo sintagmático e que apresentam links na cadeia paradigmática. Ou seja, na construção paratática, as unidades informacionais se equivalem sintaticamente e se relacionam semanticamente obedecendo a alguma ordem sancionada ou habilitada por pressões contextuais.

Ainda quanto ao subprincípio da quantidade, há uma acumulação de sentidos quando novas informações vão sendo adicionadas a velhas, como um crescendum de ideias que se sobrepõem no texto. Vejamos abaixo:

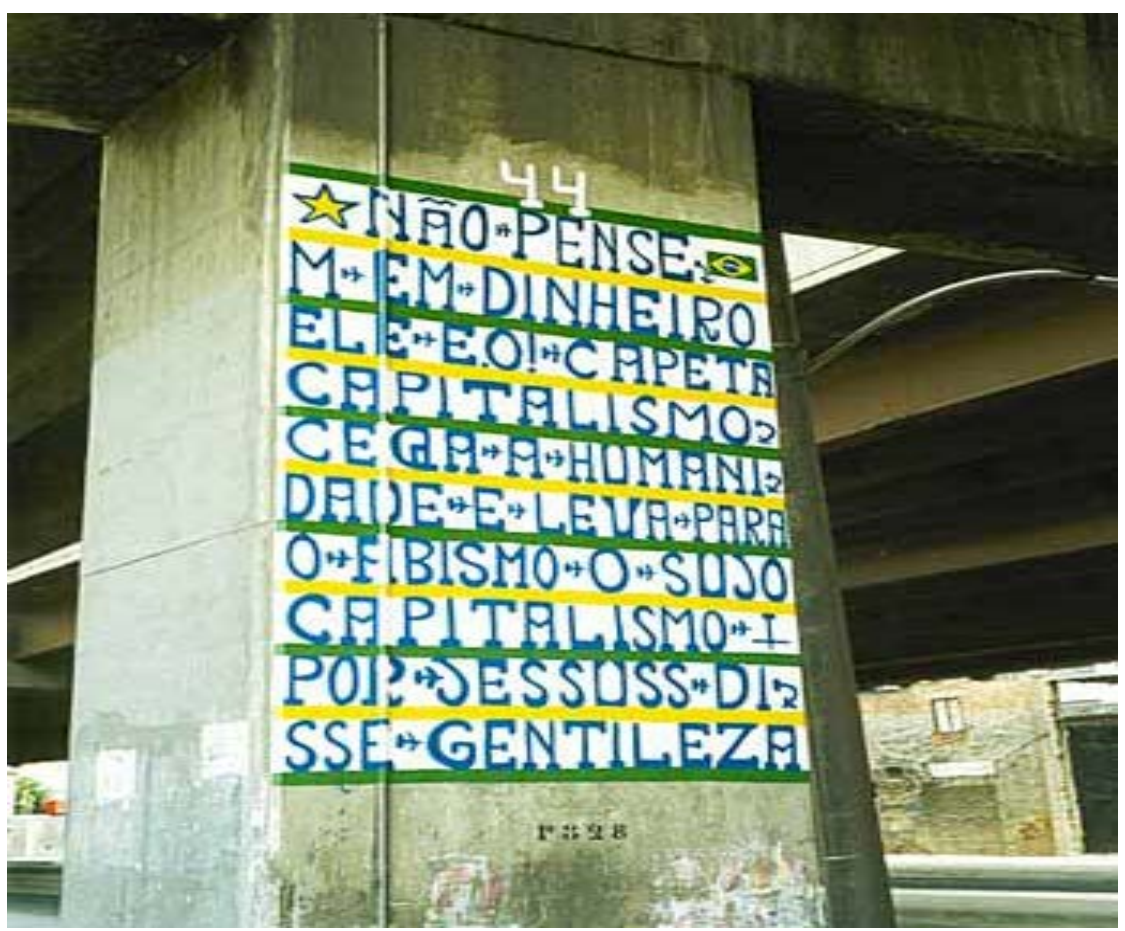

Figura 6: foto da pilastra 44

Fonte: Rio Com Gentileza (2014)

Na figura 11, temos:

1. NÃO PENSEM EM DINHEIRO (linhas 1 e 2)

2. ELEÉ O CAPETA (linha 3) 
3. CAPITALISMO CEGA A HUMANIDADE (linhas 4 e 5)

4. E LEVA PARA O ABISMO O SUJO CAPITALISMO (linhas 6, 7 e 8)

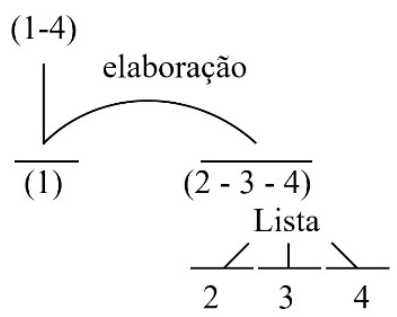

A unidade 1 é a oração primária, pois é a que carrega a lição direcionada aos leitores, segundo o propósito pragmático do profeta. As unidades 2, 3 e 4 elaboram a unidade 1, ou seja, aumentam o conteúdo semântico relacionado ao "dinheiro". Embora a relação entre todas as unidades seja por parataxe, há uma elaboração de conteúdos, postos em lista (2, 3 e 4), que vão sendo somados à ideia da unidade 1 no direcionamento do discurso e na ampliação de sentidos.

No exemplo anterior, a organização discursiva seria motivada pelo princípio de apontar o que está errado na sociedade por meio de uma sequência injuntiva (NÃO PENSEM EM DINHEIRO) e da exemplificação dessa noção para maior esclarecimento (ELE É O CAPETA...), o que é um aspecto comum nos textos didáticos. A parataxe segue como um recurso usado para explicar gradualmente a informação, utilizando mais codificação e ampliando, assim, o sentido.

Ainda com relação aos mecanismos sintáticos paratáticos, defendemos que a não utilização de elementos coesivos demanda um esforço cognitivo maior por parte do leitor, que precisa reconstruir as relações lógico-semânticas no texto, sem o auxílio de pistas sintáticas, como os conectivos. Logo, pelo menos no nível semântico-pragmático, não se pode falar em simplicidade, uma vez que as estruturas utilizadas são contextualmente dependentes, no âmbito de suas condições de produção.

Ademais, é comum que os textos religiosos e os propagandísticos trabalhem com a repetição de estruturas mais curtas, mais apreensíveis cognitivamente. A parataxe, por sua vez, está mais próxima dessa característica textual do que a hipotaxe e a subordinação. Hipotetizamos que, se Gentileza escreve em nome da divindade a fim de orientar seus filhos, a parataxe seria mais funcional, pois essas construções têm por característica serem mais diretas do ponto de vista sintático e cognitivo. Aliás, ainda segundo Longhin-Thomazi (2011, p. 238), "[...] o trabalho de elaboração mental, exigido por uma sintaxe menos explícita, tende a resultar em uma maior fixação de fatos na memória se comparado à simples recepção de algo [...] explícito”. Assim, a parataxe é também adequada devido às possibilidades de memorização desencadeadas por esse processo sintático, o que vai ao encontro das intenções do Profeta Gentileza.

\section{CONCLUSÃO}

Gentileza "cria" uma persona que representa um enviado divino, por isso seus escritos transmitem reflexões sobre a atitude dos homens diante do mundo, ensinam e apontam caminhos para a salvação da humanidade. A codificação linguística utilizada por Gentileza pode não seguir as regras da norma padrão em alguns aspectos, principalmente o ortográfico, mas apresenta uma estruturação genuinamente motivada pelo uso e eficiente do ponto de vista estético e comunicativo.

Esse tipo de texto, que tem, por um lado, uma influência religiosa muito forte e, por outro, uma veia propagandística, por servir como divulgação de ideias, favorece as estruturas paratáticas. Isso é reforçado pelo paralelismo entre as cores e pelos paralelismos sintático-semânticos. 
Assim, a pesquisa demonstrou que a parataxe seria mais funcional ao propósito comunicativo do profeta porque:

a) é composta por orações mais curtas, e mais fáceis de serem repetidas, aspecto comum nos textos propagandísticos;

b) a oposição entre bem e mal, comum nos textos religiosos, tem uma melhor organização discursiva quando expressa por parataxe, já que é algo paralelístico.

A parataxe foi recrutada em maior número, pois o objetivo era expressar conselhos e ordens de forma mais direta e rápida. As estruturas paratáticas podem alcançar determinados efeitos discursivos e pragmáticos como, por exemplo, fazer os leitores refletirem sobre a dicotomia mal $v$ s bem e, a partir dessa reflexão, sobre a sua participação no mundo. Por conta disso, acreditamos que os vínculos oracionais por parataxe constituem uma importante estratégia discursiva, já que, ao usá-los, o profeta vai motivando e/ou orientando os leitores, de forma direta e repetitiva, a seguirem, segundo ele, o que é correto.

A parataxe é uma espécie de escrita encadeada, estruturada de modo sincopado, mas que mantém o discurso coeso e coerente no momento em que as partes se juntam para formar um todo significativo. Vimos, por exemplo, que alguns textos de Gentileza produzem uma leitura adversativa em construções que não apresentam conjunção adversativa codificada. Diferentes fatores linguísticos e extralinguísticos favoreceriam essa interpretação, tendo a motivação icônica como mecanismo central. Portanto, não podemos analisar as formas linguísticas se não focamos o nível textual e extratextual. Na falta de conectores conjuntivos, que orientam os leitores para os efeitos sugeridos pelo escritor, entra em cena todo o contexto.

A ordem na parataxe é outro fator importante, pois uma inversão causaria prejuízo semântico ao conjunto textual. A inversão de segmentos coordenados pode macular o fluxo discursivo e, consequentemente, a coerência textual. Pressupomos que esse ponto seja útil para que possamos aprofundar o estudo das estruturas paratáticas, ao considerarmos que a organização das orações se faz no discurso, e não no âmbito puramente oracional ou frasal.

Necessitamos de um estudo mais amplo sobre a ordenação das orações vinculadas por parataxe, considerando os gêneros, os tipos e as sequências textuais. Consideramos o processo de articulação de orações um fenômeno discursivo, que tem o texto como unidade linguística. Diferencia-se, assim, dos estudos tradicionais, em que, como já afirmamos, a importância é dada ao nível da oração e, em alguns casos, apenas ao período, que é considerado como locus do vínculo oracional.

\section{REFERÊNCIAS}

BYBEE, J. Language, usage and cognition. Cambridge: CUP, 2010.

CARVAlHO, G. de C. Discurso religioso na loucura. 2004. 120f. Dissertação (Mestrado) - Universidade Federal Fluminense, Programa de Pós-graduação em Letras, Rio de Janeiro, 2004.

CUNHA, M. A. F.; BISPO, E. B.; SILVA, J. R. Linguística funcional centrada no uso: conceitos básicos e categorias analíticas. In: CEZARIO, M. M; CUNHA, M. A. F. Linguística centrada no uso: uma homenagem a Mário Martelotta. Rio de Janeiro, RJ: Mauad X: FAPERJ, 2013. p. 13-40.

DEVIllarT, J. M. B. A iconicidade no discurso do profeta Gentileza. 2015. 123f. Dissertação (Mestrado) - Programa de Pósgraduação em Estudos de Linguagem, Universidade Federal Fluminense, Rio de Janeiro, 2015.

FURTADO DA CUNHA, M. A.; RIOS DE OLIVEIRA, M.; MARTELOTTA, M. (Org.). Linguística funcional: teoria e prática. Rio de Janeiro: DP\&A, 2003. 
GIVÓN, T. Functionalism and grammar. Amsterdam: John Benjamins Publishing, 1995.

Syntax: a functional-typological introduction. v. I. New York: Academic Press, 1984.

GUELMAN, L. C. Brasil: tempo de Gentileza. Niterói: EDUFF, 2000.

. UNIVVVERRSSO GENTILEZA: a gênese de um mito contemporâneo. Niterói: Pontuar, 1997.

GUIMARÃES, L. As cores na mídia: a organização da cor-informação no jornalismo. São Paulo: Annablume, 2003.

HALLIDAY, M. A. K. An introduction to Funcional Grammar. London: Edward Arnold, 1985.

HOPPER, P. J.; TRAUGOTT, E. C. Grammaticalization across clauses. In: Grammaticalization. CUP: Cambridge, 2003. p. $175-211$.

LEHMAN, C. Towards a tipology of clause linkage. In: HAIMAN, J. THOMPSON S. A. (Ed.). Clause combining in grammar and discourse. Amsterdam: John Benjamins, 1988. p. 181-225.

LONGHIN-THOMAZI, S. R. Aquisição de tradições discursivas: marcas de uma escrita heterogeneamente constituída. In: Alfa: Revista de Linguística (UNESP. São José do Rio Preto. Online), v. 55, p. 225-248, 2011.

MARTELOTTA, M. Funcionalismo e metodologia quantitativa. In: OLIVEIRA, M.; ROSÁRIO, I. C. (Org.). Pesquisa em linguística funcional: convergências e divergências. Rio de Janeiro: Léo Christiano Editorial, 2009. p. 1-20.

MATTHIESSEN, C.; THOMPSON, S. The structure of discourse and 'subordination'. In: HAIMAN; THOMPSON, S. (Ed.). Clause combining in grammar and discourse. Amsterdam: John Benjamins Publishing, 198. P. 275-329.

OLIVEIRA, M. J. Conectores adversativos na fala natalense: uma análise funcionalista com implicações para o ensino. 2009. $135 f$. Dissertação (Mestrado) - Programa de Pós-graduação em Estudos da Linguagem, Universidade Federal do Rio Grande no Norte, Natal, 2009.

PEREIRA, R. Gentileza: o louco de Deus. In: Jornal da UFRJ, Ano 3, n. 34, maio de 2008, p.32. Disponível em:< http://www.ufrj.br/docs/jornal/2008-maio-JornalUFRJ34.pdf> Acesso em: 02 out. 2013.

RIO COM GENTILEZA. Disponível em: <http://www.riocomgentileza.com.br>. Acesso em: 10 jan. 2014.

RIO DE JANEIRO. Decreto no 19.188, de 27 de novembro de 2000. Determina o tombamento dos bens culturais que menciona e dá outras providências. Diário Oficial, Rio de Janeiro, RJ, 28 nov. 2000.

ROSÁRIO, I. C.; OLIVEIRA, M. R. Funcionalismo e abordagem construcional da gramática. Alfa: Revista de Linguística, São José do Rio Preto, v. 60, n. 2, p.233-259, 2016. 
TAYLOR, J. R. Linguistic categorization: prototypes in linguistic theory. Oxford: Oxford University Press, 1992.

TRAUGOTT, E. C.; TROUSDALE, G. Constructionalization and constructional changes. Oxford: University Press, 2013.

WIEDEMER, M. L.; ROSÁRIO, I. C. Língua em uso: gramática, discurso e construções. Revista Soletras, São Gonçalo - RJ, n. 2, p. 111, 2014.

WILSON, V.; MARTELOTTA, M. E. Arbitrariedade e iconicidade. In: MARTELOTTA, M. E. (Org.). Manual de linguística. $2 . e d$. São Paulo: Contexto, 2011. p. $71-87$. 